\title{
Study on Principles of Love in Architecture*
}

\author{
Marat Nevlyutov \\ Branch of the Central Institute for Research and Design of the Ministry of Construction and Housing and Communal Services of \\ the Russian Federation \\ Scientific Research Institute of Theory and History of Architecture and Urban Planning \\ Moscow, Russia \\ E-mail: mnevlyutov@gmail.com
}

\begin{abstract}
Architecture in the late XX century is criticized for the rationality, universalization and inconsistency of reality. As an alternative, the theoretician of architecture Perez-Gomez suggests the concept of love. Love is a principle that could unite inside the architectural activity knowledge and ignorance, rationality and madness, consciousness and body.
\end{abstract}

Keywords—body; incarnation; love; Eros; poetics; alitheia; ritual; phenomenology

\section{INTRODUCTION}

Since the mid-20th century, the foundations of architecture, which were formerly located in rational and abstract logic, are being critically revised. The gap between the architecture created in the pursuit of universality and the reality of uncertain and variable properties becomes evident. Architectural and urban design failures of the 20th century clearly demonstrated the crisis of architectural thinking. Theories based on different models of reality, appear, offering alternative ways to understand architecture.

So, the theorist Alberto Perez-Gomez carries out the criticism of modern thinking in architecture. He analyzes the strategies of theories and demonstrates their weakness in explaining architecture as a creative, productive process and proposes to restore the understanding of architecture as a poetic practice, the focus of which is love: "Despite our suspicions, architecture has been and must continue to be built upon love" [1]. He emphasizes the continuity of his position to the ideas of Plato's Eros, the intuition of the thinkers of the Baroque era, the concepts of phenomenology and hermeneutics.

Referring to love, Perez-Gomez moves primarily in the direction of the irrational, dark, invisible, hidden, carnal. He describes that the action of Eros in the creation of the work of art is close to poetic madness: "The incursions of Eros instruct and enrich our lives: prophets, healers, and poets conduct their art 'by losing their mind"' [2]. At the same time, for the creation of architectural theory, he retains the "rational" conceptualization of architecture, in which the

*The Reported study was Funded by Science and Technology Development State Program of the Russian Federation for years 2013-2020 Program of Fundamental Research of State Academies of Science for years 2013-2020, within the Program of Fundamental Researches of Ministry of Construction, Housing and Utilities of the Russian Federation and Russian Academy of Architecture and Construction Sciences; the Research Project 1.4.15. concepts of beauty, truth, manifestation, wisdom remain important. Analyzing Socrates, Perez-Gomez points to such dual function of love "... disruptive, transformative effect of love enables humanity to glimpse true wisdom" [3]. This article considers the unification of the opposite bases of architectural activity (visible and invisible, dark and light, irrational and rational) in Perez-Gomez work.

\section{CRITICISM OF MODERNITY}

Alberto Perez-Gomez criticizes modern architecture, which is subject to positivist, scientific logic. Space, which is created on the basis of the laws of mathematics, stands in opposition to the fluid and changeable reality, as geometry and number belong to the transcendent order, are timeless universal symbols, and therefore alienated from the "life world". Perez-Gomez insists on the humanization of space, on the return of the meanings of human existence to the architecture: "The 'spatiality' that referred to the immediate network of intention relating man's embodied being with the Lebenswelt, and that allowed for the apprehension of his place in a hierarchical order, could now be replaced by geometrical space" [4].

The first symptom that showed the alienation of architecture from the world was the emergence of architectural theory. Perez-Gomez says that the concept of "mathesis" appears already in pre-classical Greece, as a description of what can be taught or learned. The concept of "mathesis" - is the first step to "theoria", to the split of the world, understanding reality from a distance. Theory is a symbol of reality but alienated from it. The main role in the theory is occupied by scientific universals (scientia universalis), while other dimensions are expelled. The architecture that exists between geometry and craft also reorients its approach - it focuses exclusively on technical issues, eliminating the sacred and the artistic.

Perez-Gomez demonstrates the increasing role of geometry and numbers in the 17th and 19th centuries, shows the gradual mathematization of the theory of architecture. The alienation of architecture from the" life world" occurs as a result of the epistemological revolution of the 17 th century. Later in the 18th century the systematization of knowledge paves the way for universal mathematical laws that are associated with empirical observation of the world. All of this eventually forms the scientific positivism of the 19th 
century, which interprets reality entirely as a mathematical model. Thus, geometry and mathematics become detached from human meanings, values and an embodiment in the world: "Scientific thought became the only serious and legitimate interpretation of reality, denying any need for metaphysics" [5].

Knowledge consistently distances from the real world, moves toward universality, and thus towards a pure speculative character. Such aspirations also invade the field of aesthetics, where attempts to set standards, to describe the universal laws of beauty occur. The connection of geometry and desacralized numbers in architecture becomes the tool of the design process and construction technical control. The modernist architects, even those who were concerned with human meanings, could not escape this problem of thinking.

Perez-Gomez says that architecture and urbanism, following a 17th-century program, ignore the subjective interpretation of space, and the design is carried out on the basis of some objective, uninterested data: "Decisions concerning planning or the establishment of new towns, for example, continue to be made on the basis of statistics" [6]. The most uncomfortable question for 20th century architects is how a building or an activity can be justified in an existential context, what they tell about the world of "human" meanings. Constructing a building in the most effective way becomes the main concern of the architect. Perez-Gomez says that architecture comes into a conflict with the man himself, and the reason for this "...is (architect's aim) to express a mute universal process embodying the values of technology rather than to establish a meaningful framework for man's finite existence" [7].

The criticism of Perez-Gomez is mainly aimed at the scientific and instrumental approach to the design of modernist architecture and the city. But, at the same time, he sees no way out in the visuality of the postmodern architecture. For him, postmodern architecture is also captivated by the abstract thinking of the number and geometry with the only caveat that the universal laws of number are substituted with the laws of signs, which are also far from the "life world". The postmodern architects' statement about the necessity of the viewers' aesthetic satisfaction is the symptom of the alienation of the world and man in the act of consumption and enjoyment: "to See the architectural tradition only as a list of buildings with a certain practical purpose, the main of which is to give pleasure in aesthetic contemplation is a naive prejudice" [8].

\section{EMBODIMENT OF ARCHITECTURE}

In contrast to the universal and instrumental approach in architecture, Perez-Gomez proposes the concept of love, on the basis of which he forms his entire intellectual program. In the works of different thinkers (Plato, Marcilio Ficino, Giordano Bruno, Paracelsus, Jose Ortega y Gasset, Jean-Luc Marion) theorist finds reflections on love, which show the fundamental role of Eros in the creation of the world and in the creation of beauty. Perez-Gomez concludes that love is a principle with its own rationality and logic, which are far from abstract logical schemes and norms, and even surpass them in the possibility of producing meanings: "Orphic Eros is artistic power, a power of "separation" rather than deliberate, rational composition..." [9].

In the concept of love Perez-Gomez discovers the principles of architecture that allow it to be close to a man, to keep him within existence: "... it responds to a desire for an eloquent place to dwell, one that lovingly provides a sense of order resonant with our dreams, a gift contributing to our self-understanding as humans inhabiting a mortal world" [10]. Architecture cannot exist only in an abstract dimension, it always, one way or another, offers the space for understanding one's own place, for one's "existential orientation". The concept of space in which "existence is located" is articulated in the human body, so any design must resonate with the bodily living in that space or place. The perception of space does not exist separately from the structure of the body and its place in the world [11]. If the consciousness strives for the light - to the abstract, then our bodies pull us down into darkness, to an earthly existence [12].

The body, being the part of the world, connects us with it, can understand the world in spite of the so-called "scientific" meaning and Descartes' isotropic space. Perez-Gomez, following Maurice Merleau-Ponty, says that in fact we are our mortal bodies, which are one flesh with the world: "It is not so much that we have bodies, we are bodies that are in a continuous dialogue with the world" [13]. The body becomes dependent on architecture as the visible order of the world, which allows us to feel the limits of our presence in it. The theorist also shows the possibility of the immediate connection of the body and the world through love. PerezGomez, in contrast to the Western tradition to interpret love as a passion belonging to dark and natural desires, describes love as a quality of "being oriented towards the world". He finds his understanding similar to the idea of Jean-Luc Marion's love: "He claims that love does not derive from the ego and demonstrates that the opposite is true, thereby reconnecting with the Socratic tradition" [14].

But Perez-Gomez is talking not just about the bodily perception of the world, but points to the importance of the very act of incarnation. Architecture appears as a ritual action or a dance, which repeats the cosmic order: "It was assumed that participation in buildings would always involve some manner of ritual action to situate humans within the order of the world" [15]. Perez-Gomez, like his teacher Joseph Rykwert, believes that in the basis of architecture there is the ritual - the sacred action of establishing a connection between the human and the divine. The order of the ritual is fixed in artifacts, works of art, city plans, which are designed to remind the ritual by which their order was first established [16]. But it is not the ritual that refers to the universal order of space, but the program of action adjusted to the characteristics of a place. The distance between the cosmic order and the spectator disappears due to the fact that the ritual is embodied and presents itself substantively.

Perez-Gomez says that the symptom of the modernity crisis is also the illusion that a building or a city are facts independent from history. He states that it is necessary to 
discover the foundations of the created forms in social practices that were present in the form of a ritual in a particular place and time. Traditional ways of constructing history and theory of architecture avoided such ways of interpretation of space. In his search of the methods of the historical interpretation of architecture Perez-Gomez refers to phenomenology and hermeneutics (Husserl, Heidegger, Merleau-Ponty, Levinas, Gadamer) [17].

The inclusion of volatile social practices in the theory also forces the architecture to be unpredictable and uncertain. Whatever the architect creates, it falls into the social realm, which strongly alters the creation. The word said is never free from its interpretation, the audience or listeners determine the fate of the spoken and the meaning of the constructed. The modern architect, however, continues to be convinced that there is a fundamental and necessary connection between his words and reality. But in fact, the influence of the outside world has the much more significant changing force than the architect's intention: "Gadamer emphasizes, authentic artistic creation is not something that we can easily imagine being made deliberately by someone. In a profound sense, it belongs to the world" [18].

\section{POESIS AND ACTION}

According to Peres-Gomes, modern architecture is devoid of poetic content, and as a result is reduced either to the technological process or to the aestheticized form [19]. But the return of the poetic dimension is problematic, because poetry for architects is still synonymous with a sleep or madness, while the classical scientific theories remain equivalents of reality. The reality that architecture seeks to describe and change is paradoxical, therefore it cannot be described by the laws of science, it "... is always ambiguous and accessible only through the realm of "poetics"" [20].

Restoring the rights of the poetics of architecture, PerezGomez refers to the problem of the madness of love, or what Plato called an "erotic delusion". The experience of love, for Plato, is both madness and a religious insight, it is the same form of inspiration that takes possession of the poet and allows him to create beautiful works. "Plato also describes erotic delirium as a form of divine madness: possession by a supernatural power, mystic initiation with successive stages, and a final epiphany of beauty" [21].

The question that Plato raises in the discourse of love and madness is related to the relations of knowledge and ignorance. Plato's Socrates knows that he knows nothing and this knowledge is about things that are erotic, elusive, hidden, desirable. The knowledge that you know nothing is the realization of the gap between thinking and desire, consciousness and madness: "To know "what he did not know" meant to understand the ever-present gap between the thinking mind and what it desires. Never content, the mind reaches out to grasp something of which it has an inkling, something separate from itself. The path of true wisdom is always a "leaping" across an erotic space between the known and the unknown" [22].

Perez-Gomez concludes that architecture does not carry a message or knowledge, its power is in the expressed form of ignorance, the connection of the mental image and its embodiment. A man does not need knowledge, the truth reveals itself in Eros, in the desired beauty. The message of architecture arises at the moment of its embodiment: "These meanings of architecture cannot be reduced to any "message", their meaning is equal to their embodiment, as the meaning of a poem is inextricably linked with each of its sounds" [23]. As Dalibor Vesely notes, poesis also acquires its meaning and creates something that did not exist before, only being realized, manifested, represented: "The bringing into being is a creative step that transform the open field of creative possibilities into a representation articulated by gesture, word, image, or concept" [24].

Eros is like the light. It is the vessel for visible things, the way to reveal them, but at the same time it is invisible and hard to grasp [25]. Architecture as a place for dance, a place for all sorts of poetic actions creates the image in a certain language, exposing it and at the same time hiding it from the exhaustive interpretation. In this sense Eros operates in poetry by showing and hiding, approaching the meaning of Heidegger's truth - alitheia: "Martin Heidegger writes that artistic meaning, in its most fundamental sense, rests on an intricate interplay of showing and concealing; it is the embodiment of truth as alitheia" [26]. Thus, poetic architecture can be defined as the action of the incarnation of alitheia.

The return of the poetic dimension to architecture is not caused by nostalgia for the sacred past, but by a general tendency to turn to methodologies focused on artistic practices. Thus, through phenomenology and hermeneutics Perez-Gomez develops a strict theory in which love is the central concept that overcomes the duality of an idea and an embodiment, technological and artistic. His theory of architecture which is built upon love can legitimately function on the territory of any productive activity.

\section{CONCLUSION}

Modern architecture is based on abstract principles of geometry and signs, which explains its alienation from reality. According to Alberto Perez-Gomez, this situation is indicative of the "break" of representation - an unsolvable contradiction between an abstract project and its implementation in a certain place and time. The model of cognition articulated in the theory and architecture of Enlightenment led to the fundamental crisis of architecture. Hermeneutics and phenomenology, according to the theorist, open up opportunities for combining engineering and visual arts within the limits of architectural activity, in order to remove the duality of the abstract numbers and reality.

Perez-Gomez addresses different concepts: uncertainty, body, desire, madness. But the key for him is the concept of love or Eros, which he devotes a whole book to. In his opinion, the architecture built not upon love is doomed to empty formalism, functionalism or following fashion and consumerism. Love gives architecture the basis for understanding the uncertain and moving reality, connects the idea and its embodiment, knowledge and ignorance in a poetic form. The true architecture for Perez-Gomez does not 
turn into a sign or a numerical order, it is opposed to the language of prose and science but opens itself to the abyss of the possible in poetry and ritual dance.

\section{REFERENCES}

[1] Perez-Gomez, Alberto. Built upon Love: Architectural Longing after Ethics and Aesthetics. Cambridge, London: The MIT Press, 2006, p.3.

[2] Perez-Gomez, Alberto. Built upon Love: Architectural Longing after Ethics and Aesthetics. Cambridge, London: The MIT Press, 2006, p.15.

[3] Perez-Gomez, Alberto. Built upon Love: Architectural Longing after Ethics and Aesthetics. Cambridge, London: The MIT Press, 2006, p.15.

[4] Perez-Gomez, Alberto. Attunement. Architecture and the Crisis of Modern Science. Cambridge, MA: MIT, 2016, p. 10.

[5] Perez-Gomez, Alberto. Attunement. Architecture and the Crisis of Modern Science. Cambridge, MA: MIT, 2016, p. 11.

[6] Perez-Gomez, Alberto. Attunement. Architecture and the Crisis of Modern Science. Cambridge, MA: MIT, 2016, p. 7.

[7] Perez-Gomez, Alberto. Attunement. Architecture and the Crisis of Modern Science. Cambridge, MA: MIT, 2016, p. 7.

[8] Perez-Gomez, Alberto. Towards an Ethical Architecture // Ethics and Poetics in Architecture, edited by David Weir. Vancouver: BLUEimPRINT, 2006, p.67-75.

[9] Perez-Gomez, Alberto. Built upon Love: Architectural Longing after Ethics and Aesthetics. Cambridge, London: The MIT Press, 2006, p.14.

[10] Perez-Gomez, Alberto. Built upon Love: Architectural Longing after Ethics and Aesthetics. Cambridge, London: The MIT Press, 2006, p.3.

[11] Perez-Gomez, Alberto. Attunement. Architecture and the Crisis of Modern Science. Cambridge, MA: MIT, 2016, p. 3

[12] Perez-Gomez, Alberto. Built upon Love: Architectural Longing after Ethics and Aesthetics. Cambridge, London: The MIT Press, 2006, p. 3.

[13] Perez-Gomez, Alberto. Towards an Ethical Architecture // Ethics and Poetics in Architecture, edited by David Weir. Vancouver: BLUEimPRINT, 2006, p.67-75.

[14] Perez-Gomez, Alberto. Built upon Love: Architectural Longing after Ethics and Aesthetics. Cambridge, London: The MIT Press, 2006, p. 120 .

[15] Perez-Gomez, Alberto. Built upon Love: Architectural Longing after Ethics and Aesthetics. Cambridge, London: The MIT Press, 2006, p.153.

[16] Rykwert, Joseph. The Idea of a Town: the Anthropology of Urban Form in Rome, Italy, and the ancient world. London: Faber \& Faber, 2013, p. 108.

[17] Perez-Gomez, Alberto. Built upon Love: Architectural Longing after Ethics and Aesthetics. Cambridge, London: The MIT Press, 2006, p.143.

[18] Perez-Gomez, Alberto. Built upon Love: Architectural Longing after Ethics and Aesthetics. Cambridge, London: The MIT Press, 2006, p. 115.

[19] Perez-Gomez, Alberto. Attunement. Architecture and the Crisis of Modern Science. Cambridge, MA: MIT, 2016, p. 11.

[20] Perez-Gomez, Alberto. Attunement. Architecture and the Crisis of Modern Science. Cambridge, MA: MIT, 2016, p. 5.

[21] Perez-Gomez, Alberto. Built upon Love: Architectural Longing after Ethics and Aesthetics. Cambridge, London: The MIT Press, 2006, p. 14.

[22] Perez-Gomez, Alberto. Built upon Love: Architectural Longing after Ethics and Aesthetics. Cambridge, London: The MIT Press, 2006, p. 69.
[23] Perez-Gomez, Alberto. Towards an Ethical Architecture // Ethics and Poetics in Architecture, edited by David Weir. Vancouver: BLUEimPRINT, 2006, p.67-75.

[24] Vesely, Dalibor. Architecture in the Age of Divided Representation: The Question of Creativity in the Shadow of Production. Cambridge, Mass.: MIT Press, 2004. p. 15.

[25] Perez-Gomez, Alberto. The Space of Architecture: Meaning as Presence and Representation // Questions of Perception. Phenomenology of Architecture. Tokyo: A + U, 1994. p. 10.

[26] Perez-Gomez, Alberto. Built upon Love: Architectural Longing after Ethics and Aesthetics. Cambridge, London: The MIT Press, 2006, p. 115 . 